THE authors define sub-clinical lead poisoning as the production of morbidity or mortality without the appearance of the classical signs or symptoms of lead poisoning. This is a highly emotive subject and the authors are to be congratulated for dealing with it in a balanced and scientific manner. They have provided an excellent review of the literature including that and from eastern Europe, and over 1,000 With such a controversial subject it is references are given together with an author's index.

The book is divided into six main sections: lead in the environment, lead metabolism, pathological effects

\section{Natural death}

Biological Control. By C. B. Huffaker. Pp. xix +511. (Plenum: New York and London, 1974.) \$11.75.

IN recent years, increasing concern at the possible pollution of the environment by chemical pesticides has directed attention back to studies of non-chemical methods of pest control. Before DDT and other efficient synthetic insecticides were brought into general use in the $1940 \mathrm{~s}$, control of pests by biological means, particularly by parasitic or predatory insects, had resulted in many successes. Some of these, like the classical case of the Australian ladybird Rodalia cardinalis, which, in 1877 , controlled the cottony cushion scale Icerya purchasi, have never been bettered, but there have been many other successes, some partial control, and some complete failures. Nevertheless, as F. J. Simmonds has shown, the investment in research was so paltry, and the results in increased crops were so great, that the whole exercise, on a world scale, was extremely cost-effective. The trouble was often that the individual who gained could not easily be implicated in the costs of the control. Commercially produced chemical pesticides, on the other hand, could bring their financial rewards to industrial concerns.

This paperback reprint of the proceedings of a conference, aims at making up to date information about biological and other methods of pest control available to a wider audience, and particularly to university students of entomology, agriculture and allied subjects. If read critically, it should form a useful text.

Nobody doubts that, particularly when improperly used, some agricultural chemicals can endanger wildlife. the environment and even man himself. We would all like to reduce the use of dangerous chemicals, and to use non-polluting methods of pest control. But, unfortunately, some of the authors whose articles are reprinted here tend to overstate their

\section{Dangers of lead \\ by B. E. Clayton}

Sub-Clinical Lead Poisoning. By H. A. (Academic: London and May 1974.) £5.50; $\$ 14.25$.

of lead, sub-clinical effects, diagnosis not surprising that I do not agree with all the statements made but the accepted by most workers. They consider that more studies are required Waldron and D. Stoffen. Pp. $\mathrm{X}+224$. case. Thus the editor, C. B. Huffaker, says in his preface "employment of synthesised chemicals for insect pest control has posed an enormous and as yet unfathomed contribution to the degradation of our environment". This, and other similar statements, conceal the fact that over ninety per cent of pesticide usage throughout the world is effective, in that it achieves its object and no measurable damage can be demonstrated. Yet we are clearly right to worry about potential dangers, and to try to find more effective controls.

This book differs from previous texts on biological control in that although it describes once more all the well known successes, it includes a section on the ecological background to the subject and also devotes considerable space to 'integrated control' or what is now often called 'pest management'. G. C. Varley and G. R. Gradwell deal with the fundamental basis in population ecology in their paper "The Use of Models and Life Tables in Assessing the Role of Natural Enemies". An understanding of these matters is obviously essential if biological control is to cease to be a hit and miss affair. Unfortunately, these authors are still unable to demonstrate a single case where theoretical or mathematical studies have given any practical help to those engaged in practical control measures. The inspired hunch has, on the other hand, often paid off. It is to be hoped that this w'ill not discourage others from these fundamental studies, which are necessary long-term-and which, it must be accepted, may never produce the desired results.

The main lesson the book teaches is that put forward many years ago by the late W. E. Ripper: that is that an "insecticide should be used like a rapier, not like a bludgeon". This is the essence of integrated controlcouraged but when they fail the correct chemical may be carefully used. Also we are now learning that total pest natural enemies of pests should be eneradiction is neither essential nor de- before it is possible to assess whether or not excessive exposure below that causing clinical lead poisoning is producing harmless physiological or psychological effects, especially in children.

The book is well produced. The list of references would have been even more valuable if titles of papers had been given. An appendix listing quantities of lead in food and drink is included. It is written clearly and workers from various disciplines would find it valuable. I recommend it to all those concerned with this difficult environmental problem. sirable. Pests can ofiten be 'managed' to prevent patent crop damage, and, at the same time, so as to ensure the survival of their natural enemies. All these techniques will undoubtedly increase in importance, particularly if premature bans on allegedly dangerous chemicals continue to be introduced in some countries. But the farmer, and even more the medical entomologist, will rely mainly on chemicals for many years to come. It is right, however, that the disadvantages as well as the gains from chemical control should be recorded, though few writers can yet take a really objective view of the situation. KENNETH MELlaAnBy

\section{Catalogue of}

SCIENTIFIC \&

TECHNICAL JOURNALS FROM

THE U.S.S.R.

on

GEOLOGY,

GEOPHYSICS, BIOCHEMISTRY, BIOPHYSICS,

\section{NATURAL SCIENCES}

and related subjects

(in Russian but many with summaries in English) may be obtained from

Cor1 $14 t^{\circ}$

Denington Estate Wellingborough, UK 